\title{
Textbook of Oral Medicine
}

Author: Anil Govindrao Ghom / Savita Anil Ghom (Lodam)

Publisher: Jaypee Brothers Medical Publishers (P) Ltd

Language: English

ISSN: 9789351523031

Edition: $3 / \mathrm{e}$

Publish Year: 2014

Pages: 1144

Price: $£ 100.00$

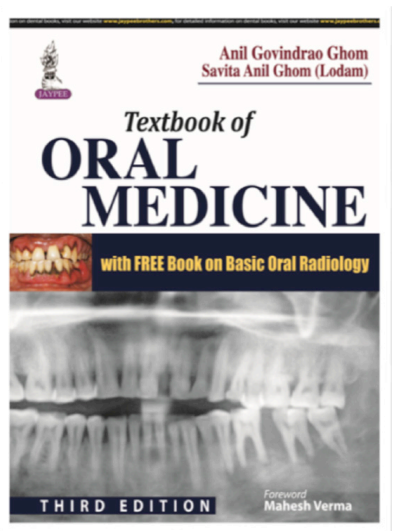

The third edition of textbook of Oral Medicine aims to provide education research and service for healthcare professionals. This last edition of the book includes lot of changes and at the end of each chapter there are multiple choice questions for revision.

The book is divided into five sections and has of a total 52 chapters. The first three sections talk about oral diseases, providing analysis of their etiology, diagnosis, histopathology, treatment and prognosis. The last two sections cover topics such as drugs used in dentistry, forensic dentistry, halitosis, controversial diseases, syndromes of oral cavity and geriatrics.

Each chapter of this textbook contains numerous clinical images, illustrations, tables and is presented in a better organization manner. The aim of this textbook is to prepare dental practitioners to better serve each patient and to understand the basic sciences related to dentistry. This new updated edition is very useful for undergraduate and postgraduate students and young dentists.

DOI: 10.25241/stomaeduj.2017.4(2).bookreview.4 